\title{
Vigilancia de Patógenos Virales Respiratorios en el Hospital de Especialidades del IHSS, 2010-2013
}

Estefanía Cuellar ${ }^{1}$, Ivette Lorenzana de Rivera, Cynthia Rodríguez ${ }^{1}{ }^{1}$ Maribel Rivera ${ }^{2}$, Rosibel Colindres $^{2}$, Sonia Ampuero ${ }^{3}$, Víctor A. Laguna-Torres ${ }^{3}$, Eric Halsey ${ }^{3}$

1: Laboratorio de Virología, Escuela de Microbiología, Facultad de Ciencias, Universidad Nacional Autónoma de Honduras

2: Instituto Hondureño de Seguridad Social ${ }^{3:}$ NAMRU 6, Lima, Perú

Introducción. Las infecciones respiratorias agudas (IRA) constituyen las enfermedades infecciosas más frecuentes del ser humano. Los agentes etiológicos que con mayor frecuencia se asocian son: los dos tipos de Virus de Influenza (A y B), el Virus Respiratorio Sincitial (VRS), Rinovirus (RVs), Virus Parainfluenza (PIV 1-4), Adenovirus, Metapneumovirus Humano (hMPV), Bocavirus Humano ( $\mathrm{hBoV}$ ) y los nuevos Coronavirus ( $\mathrm{CoV}$ ). La epidemiología de las infecciones víricas afecta fundamentalmente a los niños menores de cinco años; y en adultos las IRAs son también causa importante de morbilidad, como se vió en la pandemia de Influenza A H1N1 en el 2009.0bjetivo Realizar vigilancia epidemiológica de las etiologías virales de las IRAs en el Hospital de Especialidades del IHSS en Tegucigalpa, Honduras en los años 2010-2013.

Población de Estudio y Metodología Se captaron entre 1-3 pacientes diarios ( lunes a viernes) que asistieron a consulta externa al Instituto Hondureño de Seguridad Social con la siguiente sintomatología: tos, rinorrea, congestión nasal, fiebre $>38^{\circ} \mathrm{C}$ menor de 5 días de evolución. No hubo criterio de exclusión por edad.

Se captaron 315 pacientes que reunieran los criterios de inclusión, durante los años 20102013, después de leer una hoja informativa se procedió a la toma de un hisopado nasal para realizar prueba rápida (Influenza A e Influenza B) y un hisopado faríngeo, que fue colocado en medio de transporte y almacenado a $-80^{\circ} \mathrm{C}$ en el laboratorio del IHSS. Periódicamente se enviaron en hielo seco las muestras al NAMRU- 6 a Lima Perú, muestras del hisopado faríngeo para realizar pruebas moleculares de PCR y Cultivo con Inmunoflorescencia.

Resultados: De las 228 pruebas rápidas realizadas (62) $\mathbf{2 7 \%}$ resultaron positivas: $\mathbf{7 1 \%}$ para Influenza A (44/62) y $\mathbf{2 9 \%}$ para Influenza B (18/62). De las 315 muestras enviadas para detección de virus respiratorios, globalmente 137 (43 \%) fueron positivas: 33/64 (52\%) en el 2010,43/84 (51\%) en 2011, 27/90 (30\%) en 2012, 34/77 (44\%) en 2013; con un 59\% de positividad en menores de 5 años, del cual un $24 \%$ en niños de $2-3$ años, $18 \%$ en menores de 4-5 años y $17 \%$ en menores de 1 año. La frecuencia de virus respiratorios aislados fue: $\mathbf{5 8 \%}$ Influenza A, 23\% Influenza B, Adenovirus 7\%, Parainfluenza-3 6\%, RSV 3\%, HMPV 1\%, Parainfluenza-1 1\%, Enterovirus $1 \%$. Conclusiones: La concordancia de las pruebas rápidas con aislamiento por cultivo y PCR para Influenza A y B fue de $90 \%$. La positividad de todos los años fue de $\mathbf{4 3} \%$.El mayor porcentaje de positividad se obtuvo en el grupo etario de 2-3 años con un 24\%. Durante los cuatro años se logró aislar ocho diferentes virus causantes de Iras: flnfluenza A, Influenza B, Parainfluenza-1 y 3, Adenovirus, RSV, HMPV, Enterovirus. En cuanto a la estacionalidad de los virus causantes Iras se observó que los casos de Iras en general aumentan en los meses de lluvia en Honduras. Se recomienda continuar estos estudios de vigilancia que permiten disminuir los casos de morbilidad y mortalidad. 
